ISSN1027-5495. Functional Materials, 24, No.1 (2017), p. 117-121

doi:https://doi.org/10.15407/fm24.01.117

(C) 2017 - STC "Institute for Single Crystals"

\title{
The research of the drilling pipe's small-scale mode used in acoustic telemetry while drilling
}

\author{
Haiming Xie ${ }^{1,2}$, Jing Zhou ${ }^{2}$, Feng Zhang ${ }^{3}$ \\ ${ }^{1}$ Xidian university, Xian, 710065, P.R. China \\ ${ }^{2}$ Xian shiyou university, Xian, 710065, P.R. China \\ ${ }^{3}$ China ship scientific research center, Xian, 710000, P.R. China
}

Received December 12, 2016

\begin{abstract}
The acoustic telemetry technology while drilling has a greater advantage in the transmission rate and the application of media than the commercial mud pulse mode and electromagnetic wave mode .There are limits to the existence of the periodic drill pipe acoustic transmission transmission model, which can only calculate the acoustic transmission characteristics of two kinds of periodic structures and the acoustic transmission characteristics of the composite structures with arbitrary cross section, but the variable cross-section or various special-shaped drill strings. According to the characteristics of the small scale structure of drill string, a small scale model of the drill string in the data transmission is set up by using the theory of longitudinal vibration of structures, in which the small scale vibration transfer function of cylindrical rods with different variable cross sections is analyzed. According to certain boundary conditions, the vibration transfer characteristics of drill string are obtained, and the simulation research is completed.
\end{abstract}

Keywords: acoustic transmission; telemetry while drilling; small scale model; modeling analysis;transfer matrix

Показано, что технология акустической телеметрии в процессе бурения композитных структур имеет большое преимущество в скорости и способах передачи данных по сравнению с режимом электромагнитной волны и обычным методом измерения колебаний бура. Рассмотрены возможности метода акустической передачи данных бурильных труб, которые позволяют рассчитать акустические характеристики периодических структур и композитных структур при произвольном поперечном сечении и для различной специальной формы сверла. В соответствии с характеристиками мелкоструктурной бурильной скважины модель бурильных стержней рассматривается с помощью теории продольных колебаний конструкций, в которой анализируются малые передаточные вибрации цилиндрических стержней различных сечений.

\footnotetext{
Аналіз методу акустичної телеметрії в застосування малого буріння композитних структур. Хайлін Сье, Цзін Чжоу, Фен Чжан. Показано, що технологія акустичної телеметрії у процесі буріння композитних структур мае велику перевагу в швидкості і способах передачі даних у порівнянні 3 режимом електромагнітної хвилі і звичайним методом вимірювання коливань бура. Розглянуто можливості методу акустичної передачі даних бурильних труб, які дозволяють розрахувати акустичні характеристики періодичних і композитних структур при довільному поперечному перерізі і для різної спеціальної фрорми свердла. Відповідно до характеристик дрібноструктурної бурильної свердловини модель бурильних стрижнів розглядається за допомогою теорії подовжніх коливань конструкцій, в якій аналізуються малі передатні вібрації циліндричних стрижнів різних переризів.
} 


\section{Introduction}

The wireless measurement system has been widely used, and the system which is used the mud pulse or electromagnetic wave has been industrialized application. Acoustic telemetry while drilling using the drill string as the medium for data transmission can be less affected by drilling fluid and formation resistivity, however, the periodic variation of the cross-sectional area of the drill string and drilling noise can have a large effect on, while the rate of sound wave transmission can reach 100bps[1], which is much larger than the $3-5 \mathrm{bps}$ of the mud pulse mode. The mud pulse MWD requires mud as a transmission medium, can not be used in air drilling and foam drilling and so on. The electromagnetic wave mode is influenced by formation resistivity, and can't be applied to deep well [1-4].

The the size in the length of different components of a single drill string has a considerable size with the acoustic wavelength, here it is difficult to explain the transmission function of the drilling collar to the longitudinal vibration from the point of the wave, at this point, the different parts of the drill string mainly reflect the micro vibration transmission characteristics of the local structure, therefore, it is needed to establish a model of acoustic vibration transmission based on small scale.

It can be seen that a cylindrical rod is in the middle of the collar, and with the joints, threaded and stress decentralized structures and so on at both ends of the drill string, there are lots of linear taper hollow structure. In the long distance acoustic transmission process in multi section drill pipes, the size of the thread joint or the stress dispersion structure is so small related to the drill pipe length or the acoustic wavelength that the influence on acoustic transmission can be ignored. The drill pipe tapered transition section are simplified sectional mutation cylindrical rod to treatment[5,6]. In small scale, the design of drill pipe model needs to consider the influence of the tapered section structure on the vibration transmission.

In this paper, according to the characteristics of the small scale structure of drill string, by using the theory of longitudinal vibration of structure, the vibration transfer function of different cross section in drill string is analyzed, and the small scale transfer characteristics of drill string with different section composite structures are obtained according to certain boundary conditions[7].

\section{The establishment of transmission model}

The drill pipe is equivalent to a combination of different cross section changing bodies, then the transfer matrix of the parameters of different independent structures is analyzed one by one, which can be combined into the required drill pipe model as needed.

When the cross section of the drill string is changed, the elastic force on the cross section is changed. If the quality of drill string at $d x$ is $\rho s(x) d x$, which subjected to longitudinal stress, the vibration displacement of drill

string is $\xi+d \xi$, where $d \xi$ is the displacement increment, $d \xi=\left(\frac{\partial \xi}{\partial x}\right) d x$, and the internal elastic stress increment the drill string vibration is $d F^{1}=\rho s(x) d x \frac{\partial^{2} \xi}{\partial t^{2}}$. Because the force in the drill string is balanced, the elastic force increment $d F$ on the $d x$ part is equal to the internal elastic force increment $d F^{1}$, which cause the $d x$ to vibrate:

$$
\rho s(x) d x \frac{\partial^{2} \xi}{\partial t^{2}}-\frac{\partial}{\partial x}\left[Y s(x) \frac{\partial \xi}{\partial x}\right] d x=0
$$

The longitudinal wave velocity in the material is $c^{2}=Y / \rho$, The formula is simplified as:

$$
\frac{\partial^{2} \xi}{\partial x^{2}}+\frac{1}{s(x)} \frac{\partial s(x)}{\partial x} \frac{\partial \xi}{\partial x}-\frac{1}{c^{2}} \frac{\partial^{2} \xi}{\partial t^{2}}=0
$$

\section{A. The uniform cylinder structure}

The propagation velocity of drill string structure vibration $v=\frac{\partial \xi}{\partial t}=j \omega \xi e^{j \omega t}$, where $\mathrm{a}$ is the number of the longitudinal wave. As shown in figure 1 , the sectional area of the rod can be expressed as $s(x)=\pi\left(R^{2}-R_{0}^{2}\right)=s_{0}$ and

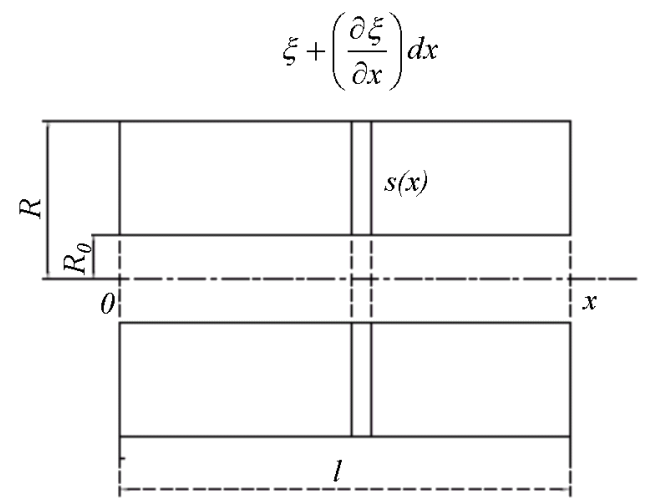

Fig. 1. Uniform cylinder structure

Functional materials, 24, 1, 2017 
the differential equation of vibration velocity is expressed as:

$$
\frac{\partial^{2} v}{\partial x^{2}}+k^{2} v=0
$$

Can get:

$$
v=A \cos (k x)+B \sin (k x)=A_{0} \sin (k x+\delta)
$$

The acting force in the rod is:

$$
F=j \rho c s(x)[A \sin (k x)-B \cos (k x)]
$$

When $x=\mathbf{0}$

$$
\begin{gathered}
v_{1}=A \\
F_{1}=-j z B
\end{gathered}
$$

When $x=l$,

$$
\begin{gathered}
v_{2}=A \cos (k l)+B \sin (k l) \\
F_{2}=j z[A \sin (k l)-B \cos (k l)]
\end{gathered}
$$

\section{B. The equal thickness conical rod}

As shown in Figure 5 in the ends of the drill collar. The wall thickness of hollow conical rod with equal wall thickness is

$$
h=\left(R_{\text {out } 1}-R_{\text {in } 1}\right) \cos \alpha
$$

If $\tan \alpha=\frac{R_{\text {out } 1}}{d_{1}}=\frac{R_{i n 1}}{d_{2}}=D$, the section radius of tapered rod is:

$$
\begin{gathered}
R_{\text {out }}(x)=R_{\text {out } 1}+D x \\
R_{\text {in }}(x)=R_{\text {in } 1}+D x
\end{gathered}
$$

The cross sectional area:

$$
\begin{gathered}
s(x)=\pi\left[R_{\text {out }}^{2}(x)-R_{\text {in }}^{2}(x)\right]= \\
=\pi\left(R_{\text {out } 1}-R_{\text {in } 1}\right)\left(R_{\text {out } 1}+R_{\text {in } 1}+2 D x\right) \\
\frac{\partial s(x)}{\partial x}=\pi 2 D\left(R_{\text {out } 1}-R_{\text {in } 1}\right)
\end{gathered}
$$

Combined with vibration equation, can get:

$$
\frac{\partial^{2} v}{\partial x^{2}}+\frac{1}{\left(\frac{R_{o u t 1}+R_{i n 1}}{2 D}+x\right)} \frac{\partial v}{\partial x}+k^{2} v=0
$$

The general solution formula:

$v(x)=A J_{0}\left[k\left(x+\frac{\bar{R}_{1}}{D}\right)\right]+B N_{0}\left[k\left(x+\frac{\bar{R}_{1}}{D}\right)\right]$

The acting force on the cross section is:

$F(x)=$

$=-j \rho c s(x)\left\{A J_{1}\left[k\left(x+\frac{\bar{R}_{1}}{D}\right)\right]+B N_{1}\left[k\left(x+\frac{\bar{R}_{1}}{D}\right)\right]\right\}$

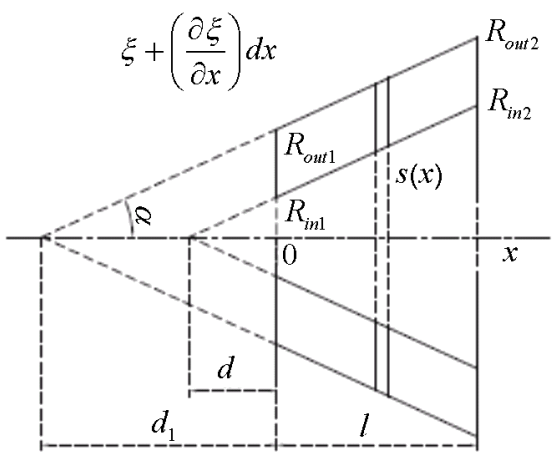

Fig. 2. The equal thickness conical rod

When $x=0$

$$
\begin{gathered}
v_{1}=A J_{0}[M]+B N_{0}[M] \\
F_{1}=-j z_{1}\left\{A J_{1}[M]+B N_{1}[M]\right\}
\end{gathered}
$$

When $x=l$

$$
\begin{array}{r}
v_{2}=A J_{0}[k l+M]+B N_{0}[k l+M] \\
F_{2}=-j z_{2}\left\{A J_{1}[k l+M]+B N_{1}[k l+M]\right\}
\end{array}
$$

among them:

$$
M=k \frac{\bar{R}_{1}}{D}, z_{1}=\rho c s(\mathbf{0}), z_{2}=\rho c s(l) .
$$

According to the working conditions, consider the following boundary conditions:

1) if $F_{2}=0$, the output under free boundary condition:

$$
\begin{aligned}
& Z_{12}=\left|M_{21}\right|=\left|\frac{F_{1}}{v_{2}}\right|_{F_{2}=0} \\
& H_{12}=\left|\frac{1}{M_{21}}\right|=\left|\frac{v_{2}}{F_{1}}\right|_{F_{2}=0}
\end{aligned}
$$

Among them: $Z_{12}$ is the structural vibration transfer impedance relationship from input to output; $H_{12}=\left(Z_{12}\right)^{-1}$ is the transfer admittance characteristics for structures.

2) if $v_{2}=0$, the output under fixed boundary condition:

$$
\begin{aligned}
& Z_{21}=\left|\frac{1}{M_{12}}\right|=\left|\frac{F_{2}}{v_{1}}\right|_{v_{2}=0} \\
& T_{f}=\left|\frac{1}{M_{22}}\right|=\left|\frac{F_{2}}{F_{1}}\right|_{v_{2}=0}
\end{aligned}
$$

Among them: $T_{f}$ is the transfer force ratio at both ends of structure under fixed boundary conditions; $Z_{21}$ is the vibration transmissibility impedance relationship between output and input. 


\section{The comparison of simulation experiment}

In order to verify the validity of the solution of the vibration equation and the transmitting method, using 9 standard drill pipe assembly model of Douglas, then calculates the characteristic parameters, analysis the change rule of the vibration with frequency in the drilling string [8-20].

As showed in figure 3 and figure 4, the vibration response curve calculated by the small scale vibration transfer method is compared with the sound pressure transfer curve, which is calculated by Douglas finite difference method, in $850 \sim 1300$ frequency bands. Two conclusions can be obtained from:

a) The results of the two methods agree exactly in the frequency domain.It shows that the transfer performance of the structure to the force and velocity is the same, whether the excitation is force or speed, the two transmission parameters are completely consistent.

b) In the band-pass frequency domain, the resonance peak number and the corresponding frequency point position are completely consistent in the structure. The transfer coefficient of the small scale vibration model has obvious sawtooth peak, and some value is greater than 102 order, but there is no such calculation result in the finite difference model, the maximum of the total transmission coefficient of which is 1 . It shows that the structure has amplification effect on the vibration transfer, which is caused by the periodic expansion of the structure. The small scale vibration model is more accurate than the finite difference method.

\section{Simulation experiments under different output boundaries}

When the output boundary end of the structure is free, the transmission impedance curves in the passband of $0-5 \mathrm{kHz}$ are shown in Figure 5. In band stop band, the higher transmission impedance leads to smaller vibration at the output.In the pass band, the transmission impedance of the structure to input vibration is lower, the vibration to the output end is larger, while is under the same excitation force, which forms the vibration peak value.

If the output is in a fixed boundary condition and the structure is under speed excitation, the variation of the output force at the frequency is opposite to the structural vibration transfer impedance under the free boundary condition.

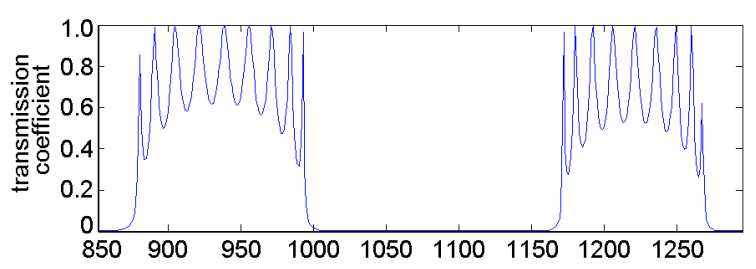

Fig. 3. Acoustic band pass characteristic of $850 \sim 1300 \mathrm{~Hz}$

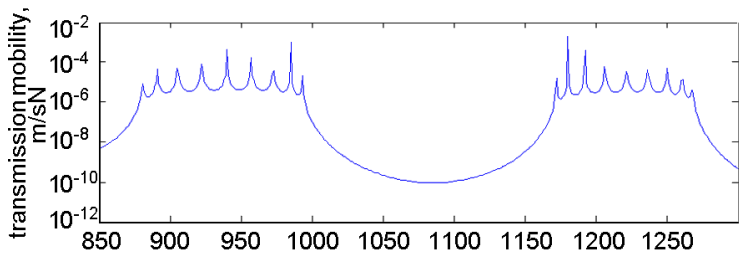

Fig. 4. Band structure admittance response curve of $850 \sim 1300 \mathrm{~Hz}$

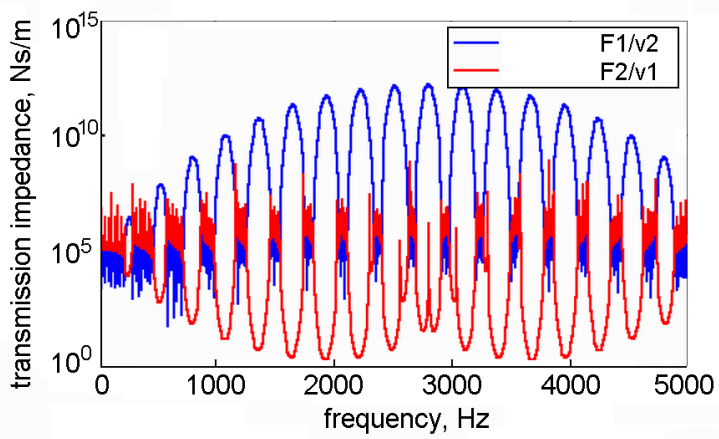

Fig 5. Comparison of structural transfer impedance under two boundary conditions

It shows that the larger transfer impedance in the structure, the smaller vibration displacement of the output under input velocity excitation. If the impedance of a frequency point the structure is small, the vibration displacement of the output end is larger under the excitation of the input velocity, while the output is just under the fixed condition, so the force is larger.

\section{Conclusion}

In this paper, the vibration transfer equations of variable sections of drill string are analyzed, and the indexes of vibration transfer parameters of drill string under different boundary conditions are obtained. The characteristics of the small pass drill string vibration transfer method of this paper are compared with the traditional finite difference method. It can be seen that the structure has amplification effect on vibration transfer in the method, while the small scale vibration model is more accurate. By comparing the structural transfer impedance under free and fixed boundary conditions, it can be seen that the structural transfer frequency is completely consistent. 


\section{Acknowledgments}

This work was financially supported by the Shaanxi province key disciplines special funds of instrument Science and technology(No. YS312010004), the scientific research and technology development project of CNPC (New drilling technology and new methods, No.2011a-4206) and (Development of measurement and transmission equipment while drilling, No.2014B-43), the major national R\&D projects (Rotary steering and mud logging while drilling, acid gas layer testing technology and equipment, No.2011ZX05021-005) .

\section{Reference}

1. Li Chao. The research and development of MWD data acoustic transmission technology based on drill pipe [D].China University of Petroleum, 2010.

2. Cao Litian. The research of acoustic sending and receiving electronic system along drill strings [D]. China University of Petroleum, 2011.

3. MA Zhe, Yang Jinzhou, Zhao Jinhai, Petrol. Drill. Techn., 35(6): 112, 2007.

4. Tu Bing. MWD mud pulse signal identification and ground adaptation technology research[D]. Beijing University of Technology, 2013.

5. Li Cheng, Jing Zhongwu, Liu Zhao.. J. Vibrat. Shock, 32(22): 53, 2013.
6. Duan Zhifeng. The structure design of MWD acoustic telemetry system of oil and gas wells [D]. China University of Petroleum, 2011.

7. Haiming Xie,Jing Zhou,Feng Zhang, Open Petroleum Engin. J., 8(1), 427, 2015.

8. Douglas S. Drumheller. Acoustical properties of drill strings [J]. J.Acoustic Soc. Am., 85(3), 1989.

9. L.Cremer, Structure-Borne Sound, SpringerVerlag Berlin Heidelberg 2005.

10. Frank Fahy. Sound and Structural Vibration, Published by Elsevier 2007.

11. Nie Jianhua. Research on Piezoelectric Transducer Consistency Screening Technology and Sound Isolator Design Technique [D].Tianjin University, 2009.

12. Yan Xianghong, Su Yuanda, Sun Jianmeng, Chinese J. Comp. Phys., 27(6), 82, 2010.

13. Zhuang Chunxi. Numerical simulation and Experiments on isolator Logging-While-Drilling (LWD) acoustic tool [D]. China University of petroleum, 2011.

14. Zhang Meiling. Numerical simulation investigation on sound isolator of acoustic logging while drilling [D]. China University of Petroleum, 2011.

15. Su Yuanda, Zhang Chunxi, Deng Line, Li Yuxia, Qin Yukun.. Well Logging Techn., 35(5), 402, 2011.

16. Wang Guoping, Petroleum Instr., 24(4), 1, 2010.

17. Liu Bin, Wang Fang, Chen Dehua, Che Chengxuan, Appl. Acoustics, 31(5): 333, 2012. 